\title{
Making Sense of Weick's Organising. A Philosophical Exploration
}

\author{
Suzan Langenberg ${ }^{1} \cdot$ Hans Wesseling ${ }^{1}$
}

Published online: 30 May 2016

(C) The Author(s) 2016. This article is published with open access at Springerlink.com

\begin{abstract}
According to Karl Weick, a distinguished scholar in Organizational Behavior and Psychology, the organization cannot be imagined as an architectural design, static and prescriptive, but should be described as a Jazz improvisation, a flexible mental model. By conceiving both the organization and its environment as a social and mental construct, we are able to get a better view on the denotation of the individual factor. In his approach the dichotomy between theory and practice dissolves. The organization is studied as an activity. These dynamics (dis)continuously generate sense. Because of his radical choice for understanding the organization as dynamic and without ground, his thinking has parallels with post-modern thinking. In his description of the characteristics of organizations, he identifies as sixth element, ongoing. This concept is only conceivable in its disturbance, its interruption. Herein we sense affinity with the post modern deconstruction concept (Derrida). With interruption, aspects like misunderstanding, failure, mistakes, conflict, contradiction and exclusion get a role in understanding the organization dynamic. In order to manage the resulting confusion, individuals, in social interaction, actively make sense of that experience retrospectively. In organizations, managers and employees alike, are essential in signaling interruptions and the contribution to the process of sensemaking. Managers are expected to take the initiative in facilitating the open space in which judgment is temporarily suspended. Managing becomes the managing of sense, sharing of meaning, of diversity and oppositions.
\end{abstract}

Keywords Sensemaking $\cdot$ Interruption $\cdot$ Meaning $\cdot$ Dis-organising

\section{Introduction}

What is an organisation? Is it a building, a name, a brand, a production-unit, a sole proprietorship, a group of people? Can we call the internet, Facebook or modern networks 'organisations'?

Suzan Langenberg

s.langenberg@diversity.be; http://www.campusgelbergen.be

1 Diversity - Campus Gelbergen, Hoeleden, Belgium 
About 150 years after the introduction of organisational theory, not only organisational practice has changed drastically, but moreover, the theoretical reflections on what an organisation actually is, are more and more apart. Where the organisation was a result of 'calculative thought' ${ }^{1}$ at first - engineers who, based on logical/rational reasoning, drew a production process and established it on a defined location - now it seems as if nearly any activity can be labelled with the word 'organisation'.

We can think of numerous causes to explain these changes, both in theory as in practice. The visibility of the human factor in 'organising' from the 1930s for instance, or the rise of globalisation after WWII, the unstoppable technological innovation since the 1960s, the anticipation on environmental effects of industrial activities starting mid-1970s or the financial instability and stagnation since 2008. There are enough reasons to re-think production processes, to re-locate production units, to make new legislation and transform old industries to high tech multi stakeholder networks. Reasons to take action are usually short-term reactions to external change. The initial premise on which organisations are built - the conviction that the organisation can be manufactured - is still dominant, while the practice of organising shows us a different reality.

Organisational psychologist Karl Weick, a distinguished scholar in organisational behaviour and psychology, is one of the few organisational theorists of the last century to approach the organisation starting with a fundamental question which contains all elements of human action and its complex effects: How can I know what I think until I see(hear) what I do? We think that this is a philosophical question, where poeisis and praxis apparently come together in personal judgment. Because Weick distances himself from a static organisational concept which is mostly concerned with structure, hierarchy and the division of tasks and responsibilities, he creates the opportunity to understand modern dynamic, constantly regenerating communicative networks as organisation. With a critical understanding of organisations, the relationship between the organisation and the individual act can also be expanded and the question about the role of the organisation in the world today can be asked in a different way.

In this essay, we will take a closer look at the starting question from Weick's organisational theory by using some of his core concepts. Although it clearly appears that his conceptions can explicitly be linked to the German modern and French postmodern thought, Weick only sporadically refers to philosophy. We want to compensate this 'lacking' at some points in this article.

First we will introduce his organisational perspective: how Weick describes the shell of an organisation enables his specific approach ofthe (organisational) act. Subsequently we will contextualise his concept of sensemaking bringing in some philosophical insights, something Weick hardly did himself.

\section{Notions}

\section{Organising $=$ dis-organising?}

Weick defines an organisation as organising. He confirms that the organisation cannot be imagined as an architectural design, static and prescriptive, but should be described as a flexible mental model wherein the dichotomy between theory and practice dissolves.

\footnotetext{
${ }^{1}$ German philosopher Martin Heidegger opposes calculative thinking to essential thinking. See also 'Calculative Thinking and Essential Thinking in Heidegger's phenomenology' by John D. Haynes.
} 
The recipe for disorganization reads: Thrust people into unfamiliar roles, leave some key roles unfilled, make the task more ambiguous, discredit the role system, and make all these changes in a context in which small events can combine into something monstrous. Faced with similar conditions, organizations that seem much sturdier may also come crashing down, much like Icarus who overreached his competence as he flew toward the sun and also perished because of fire (Daft and Weick 2001: 109-110).

Weick comes to this description of dis-organisation by re-writing the classical notion of organisations. ${ }^{2}$ In Organisational Redesign as Improvisation, Weick counters the metaphor in which the organisation is represented as an architectural design. The order that originates in jazz, a musical improvisation, is made by the musicians and comes into being in a stream of common experiences. That order is the orchestra and only exists in the heads of the members of the orchestra (Weick 2001: 201). That is how Weick understands the reality of organisations. A reality that is stable and unstable, ambiguous and unambiguous at the same time, in short: the idea of the organisation as a mental construction which is made by individuals and merely exists 'in their heads'. A notion of THE organisation does not exist outside the process that generates this concept. Parts of that stream of experiences are even indescribable and incomprehensible (Weick 1979: 12). Therefore, if we want to gain insight into what 'the organisation' could mean, we need to look at the origin itself of the concept in an acting and communicative de-sign, a circularity of creation of meaning which has neither a beginning, nor an end. With the translation de-sign we want to stipulate the simultaneously creative, constructive and disconnecting or decoupling effect of organising. De-sign expresses the unsigning, the disconnection of the sign character, the referential character. After all, there is nothing it can refer to except for its own construction. A design is not constructed at a single point of time but is continuously reconstructed because of unplanned changes, personal interpretations of facts and the transient character of designs.

In the following scheme, we can see Weick's vision on the organisation (right column) in a reaction to the CODE study of Khandwalla (1977) (left column), who proposes the organisation as an architectural design (Table 1):

This exercise shows us that Weick discards the traditional design of an organisation of its presupposed static, prescriptive way of operating, and presents it as a flexible conceptual model.

If designs originate in ideas, interaction, shifting competencies, and retrospect, then organizations should be characterized by a succession of short-lived designs that evaporate rather than erode. Designs disappear abruptly rather than fade because they are competence-specific. As competence changes, so too does design (Weick 2001: 85-86).

In this exercise, he prioritises organisational practices, the act. As a consequence, the modernist paradigm which is the foundation of classical organisational thinking, transforms. In short, according to Weick: "To design is to notice sequences of action that are improvements, call attention to them, label them, repeat them, disseminate them, and legitimize them (Weick 2001: 88)".

\footnotetext{
${ }^{2}$ Cfr. Jean-François Lyotard: 'Re-ecrire la modernité', the creation of a new discourse - in spite itself - namely that of postmodernity. As a philosopher, Lyotard has not identified with - but also not extremely opposed against - the postmodern discourse. By continuously confronting himself with the question : "How can I know what I think until I see what I do", we see a similar detachment from existing or projected discourses with Weick, "that phrase has haunted me most of my professional life (...) and can be seen as a recipe for organizing and sensemaking..." (Making Sense of an Organization) p.95.
} 
Table 1 This table shows the Khandwalla perspective on an organisation as an architectural design on the left with the opposite perspective of Weick - the organisation seen as an improvisation - on the right

\begin{tabular}{ll}
\hline Architecture & Improvisation \\
\hline
\end{tabular}

Implied assumptions

The design of an organisation determines

A design is a blueprint

A design is constructed at a single point in time

Design produce order through intention

Design creates planned change
Alternative assumptions

A design is a recipe

Designing is continuously reconstructed

Design produce order through attention

Design codifies unplanned change after the fact

The design of an organization determines the distribution of resources, authority and information

An organization has only a single design

The design determines the distribution of resources

Designs are large structures that are stabilized
An organization has multiple designs

The distribution of resources determines the design

Designs are small structures that are amplified.

Design' impacts the ability of the individual manager'

Design affects managerial ability

Managerial ability affects design

Managerial action is social

Designs affect 'the ability to make and implement' 'timely... sound and... acceptable decisions'

Decisions determine effectiveness

Interpretations determine effectiveness

The purpose of design is to facilitate decision making

People decide and then they act

The purpose of design is to facilitate interpretations

People act and then they interpret

Manager's ability to coordinate and control the activities of subordinates
Controlis differentially distributed
People impose controls
Control is equally distributed
Activities are the object of control
Ideas impose controls
Ideas are the object of control

Proper organizational design can therefore make the difference between having an effective, well-run organization and one having recurrent crises and organizational inefficiencies

An effective organization has few crises and inefficiencies

Recurrent crises and inefficiency reduce current effectiveness

Proper organisational design reduces current inefficiency
An effective organization has many crises and inefficiencies

Recurrent crises and inefficiency increase future effectiveness

Proper organisational design exploits crises and inefficiencies

Organizational environments are changing... rapidly... \{which $\}$ erodes \{the effectiveness of an organizational design $\}$ over time

Environments change more rapidly than do organizations

Designs construct organizations to fit environments

Designs are relatively permanent
Organizations change more rapidly than do environments

Designs construct environments to fit organizations Designs are relatively transient

By conceiving both the organisation and its environment as a social and mental construct, we are also able to get a better view on the denotation of the individual factor. A dynamic understanding of the organisation puts organising as 'acting' up front and incorporates the interaction with the environment in its own understanding. This implies the continuous appearance of incoherencies and inconsistencies. For Weick, an organisation 'lives' in an environment where living and working go equally together. 
Officially, Weick's theory is often classified under social constructivism, the theory which assumes that the world does not occur to us as a fixed given and can only be known in its 'groundlessness'. ${ }^{3}$ His radical choice for understanding the organisation as dynamic and without ground, shows parallels with post-modern thinking, although Weick himself doesn't make this connection (Langenberg 2008: 114-118; Langenberg 2011: 103-104). Paradoxically, in his description of an organisation as a de-sign 'continuously re-constructed' we sense affinity with the post-modern concept of deconstruction, first described by the French philosopher Jacques Derrida. ${ }^{4}$

Each time that I say 'deconstruction and X (regardless of the concept or the theme),' this is the prelude to a very singular division that turns this $\mathrm{X}$ into, or rather makes appear in this $\mathrm{X}$, an impossibility that becomes its proper and sole possibility, with the result that between the $\mathrm{X}$ as possible and the 'same' $\mathrm{X}$ as impossible, there is nothing but a relation of homonymy, a relation for which we have to provide an account.... For example, here referring myself to demonstrations I have already attempted ..., gift, hospitality, death itself (and therefore so many other things) can be possible only as impossible, as the impossible, that is, unconditionally (Mallet and Michaud 2004: 21-34 ; Derrida 1972 : 56-57).

The groundlessness of an organisation exists in its endless urge desperately looking for grounds. This never ending dynamic as such creates ambiguity. In order to grasp reality, it is not the opposition but the inclusion of two counter positions we need to think of. With the name deconstruction (a combination of destruction and construction) Derrida dissociates himself from modern thinking: the deconstructive 'reading' of reality is never final, it opens 'ongoing' new perspectives and meanings and simultaneously elicits its contradictions.

With the concept of deconstruction, Derrida builds on analyses of the German philosopher Martin Heidegger. Therefore, we shall clarify the notion of 'groundlessness' according to Heideggers notion of 'the essence of ground'. In Der satzvomGrund, Heidegger writes about the word for principle (Satz)as a saying, as Andenkend - Vordenkender, as a jump, a musical sentence (tone, composition). For him, 'jump' also refers to the possibility to see the take-off, the onset of the jump, in retrospect. Heidegger points out that 'the jump' (der Satz) (Heidegger 1996: 9) leaves the outlet, and at the same time regains what it leaves behind, andenkend, so the former possibilities become only now inalienable. He furthermore says:

That into which the leap anticipatorily leaps is not some region of things present at hand into which one can simply step. Rather, it is the realm of what first approaches as worthy of thought (Heidegger 1996: 89).

As we will see further on in this essay, it is not difficult to see a relation between the quote above and what Weick understands with retrospective sensemaking. It is a different way of formulating Weick's well-known sentence. This sentence also points at the andenkend which becomes possible because of the jump. In Weick's words, we can understand 'jump' as 'interruption'. It also is not a given new terrain which we can enter no matter what, it is an area which only becomes possible because of the jump, and also gives us an insight into where

\footnotetext{
${ }^{3}$ Sensemaking in Organizations, p. 38. Weick cites Varela et al. "groundlessness is the very condition for the richly textured and interdependent world of human experience.... The world is not pregiven but continually shaped by the types of actions in which we engage".

${ }^{4}$ Weick dissociates himself from postmodernist thought with a very brief and cryptic argumentation at (1995: 37) although we see several clear parallels between his theoretical premises and those explored by postmodernists as Jacques Derrida and Jean-François Lyotard.
} 
we come from. The 'immediate sense' as Weick calls it, is the starting point of the sensemaking process, a previously established sense. Its track remains present as track.

What we can also read is the perspectivist character of the jump, the fact that it makes a new area, it 'thinks ahead'. Here it becomes clear that the criticism of the supposed 'not being future-oriented' of Weick's sensemaking can be countered by referring to Heidegger's Satz. Sensemaking, the jump, opens up a new terrain. It carries the 'mark' of former possibilities as Heidegger says, and Weick will agree because he takes 'experience' and the above mentioned 'immediate sense' as the key-point of the sensemaking-process. It certainly is a jump. That is why organisational dynamics (dis)continuously generate sense.

When Heidegger speaks of the 'change of the tone' (the German word Satz means besides 'jump' also 'tone' and 'composition') and consequently of a change of meaning, or the opening up of new meanings, we also conceive it in a musical sense (keeping in mind the jazz metaphor of Weick). With regard to this theme, Heidegger refers to Bettina von Arnim, who writes:

If one speaks of a movement [Satz] in music and how it is performed, or of the accompaniment of an instrument and of the understanding with which it is treated, then I mean precisely the opposite, namely that the movement leads the musician, that the movement occurs, develops and is concentrated often enough till the spirit has completely joined itself to it (Heidegger 1996: 89).

\section{Sensemaking}

Sensemaking is a pivotal concept for Weick. Firstly, because he regards organisations as 'sharing of meaning', and secondly because sensemaking is the foundation of the dynamic that determines the survival of organisations. By taking (organisational) practices as a starting point, various different theoretical concepts are involved in interpreting and solving problems. On a theoretical level, assumptions can conflict with each other, but these discrepancies are subordinate to "(...) sensemaking as an activity which by virtue of constructing, filtering, framing, create facticity and render 'the subjective' into something more tangible (1995: 14)".

Weick (1995: 55) formulates the process from de-sign to sense as follows:

Once people begin to act (enactment) they generate tangible outcomes (cues) in some context (social) and this helps them discover (retrospect) what is occurring (ongoing) what needs to be explained (plausibility) and what should be done next (identity enhancement) (...) Sensemaking starts with three elements - a frame, a cue, and a connection - with frames tending to be past moments of socialisation and cues tending to be present moments of experience (1995: 111)'.

Acting creates retrospect, enactment equal to sense which is being constructed again and again in the development of the event. Weick indicated that it is incorrect to speak in terms of 'result' of the sensemaking-process, because this would ignore the continuity of that process:"there is no result of process but only a moment in process." The basis of the sensemaking-process, 'a frame', is built on an 'immediate sense', a temporary position which is taken from the past. This simplified, ordering reading of events, leads to more effective future action. The frame is also a construction which has been brought about retrospectively and therefore concerns a processed experience.

Sensemaking is a constructing process of awareness which results in "a developing set of ideas with explanatory possibilities". The latter should not be understood as 'a body of 
knowledge' however, according to Weick. Rather, these are possibilities of clarification that have to be brought about over and over. Weick endorses Cohen, March and Olson's provocative notion that 'rationality is in the eye of the beholder'. They formulate it as follows:

(...) an organisation is a collection of choices looking for problems, issues and feelings looking for decision situations in which they might be aired, solutions looking for issues to which they might be the answer, and decision makers looking for work (1979: 2).

Weick gives the impression that he turns his back on a rational approach of the organisation. He does, however, look for ways to make the organisational dynamic understandable and tangible. This is why he questions concepts such as 'surrounding', 'goal', 'continuity', 'leadership', 'planning' and 'rationality'. According to Weick the idea of a stable world is a Carthesian errancy, but he neither wants to fall into the pitfall of idealism, nihilism or some sort of subjectivism. In his words we are clearly dealing with a fear that there is no stable world out there. $^{5}$

Nothing is what it seems, everything is subject to a (dis)continuous 'change'. Weick's understanding of what an organisation could be, is connected with his conception of the constructive character of sensemaking. This construction is best described as 'inner coherence', an experienced constructed totality which distinguishes itself from the necessary inner coherence that concerns an essential coherence. It is a totalising, self-validating construction. After all, there is no 'underlying reality waiting to be discovered', therefore it cannot be normative.

With Weick, we see that through the process of sensemaking, a factual, meaningful, 'being-such-unity' is created. That creation of unity or coherence, is the necessary condition for Sense, meaning. ${ }^{6}$ There, sense determines the capacity of the experienced truth, not the ontological truth. Not 'language' and 'being', but 'speech act' and 'beinghow' are important in this case. Therein, Weick sees an analogy with reading, which connects words and sentences into a whole, one text, which retrospectively comes into being as an inner coherent story in the act of reading. It is potentially there as possible totality, but only evolves through reading and speaking. The synchronic totality is present as sense in the diachrony of the act as possibility and as 'developing' as well, but retrospectively it is constructed as unity.

We have named a few important aspects of Weick's sensemaking process. It is a construction that in its nature temporarily gives sense, which is established retrospectively. That temporality derives from the (dis)continuity of the sensemaking-process. We have already seen that Weick prefers act over thought, since he defines the organisation as 'organising'. In his core sentence "How can I know what I think until I see (hear) what I do?", 7 he repeats this insight. The act precedes understanding, sense. We also have a first presumption about the nature of that sense. According to its nature, it is complete. It is impossible to step out of it except by taking action. The process of sensemaking unfolds again and again and (re)creates meaning, the understanding of reality and one's own identity. Reality and identity are fluid

\footnotetext{
${ }^{5}$ ibid. p. 37 and also see Weick'slatest book together with Kathleen M. Sutcliffe (2007), Managing the Unexpected, where he describes different practical situations where there is being dealt with fear and the unexpected on an organisational level.

${ }^{6}$ See also Van Den Hengel (1982) in The Home of Meaning. (pp. 98). There, he cites Dilthey and agrees with him. In this essay, like Weick, we use the concepts 'sense' and 'meaning' synonymously.

${ }^{7}$ See, amongst others (Weick 1995: 12; Weick 2001: 463). It is the wording of the sensemaking process, one of Weick's core concepts.
} 
concepts whose meaning changes regularly. ${ }^{8}$ In the next paragraph, we shall further discuss sensemaking as a shared mental construction ('shared meaning'), which is established retrospectively, based on shared experience and changes (dis)continuously.

\section{Sharing of Meaning}

Weick indicates that there can be numerous reasons to coordinate acts, and that "shared meaning is not what is crucial for collective action but it is the experience of the collective action that is shared" (1995: 42). He does not aim at the realisation of an identical sense, or to reach an agreement on a shared experience of reality. 'Sharing of meaning' has to be taken literally as activity, not as a result! The temporary establishment of meanings, the fact that they are shared in that process and their transformation to a new reality is a form of critical practice. Only after the sharing, a new 'reality' comes into being. ${ }^{9}$

This common action, these 'working' relations, can originate in individual considerations aimed at realising individual goals. Common goals are therefore not crucial for common action. The fact that not the individual, but the relationship -the joint behaviour - is the nucleus of organising, has as a consequence that the attention of the 'aware individual' moves to the 'acting individual'. In other words, all action within the organisation is relevant because it contributes to common experience, the basis for sensemaking.

\section{Construction of Identity}

Identities are (de)constructed in a process of interaction, and the sensemaker redefines himself continuously in the shift that is triggered by these interactions. The definition of the self is not (pre)-)given, but on the contrary the result of the out there. It is a dynamic structure of interpretation that mediates between intra- and interpersonal processes. What underlies these processes, is the psychological need to lift tensions and oppositions and to come to a 'sense of identity', a general orientation with respect to situations that maintain an appreciation and consistency of someone's self-understanding. If that is not affirmed, that tension will give rise to renewed sensemaking. The basic presumption here is that sensemaking is self-referential, which means the 'self' and not the 'environment' is 'the text that asks for meaning'. Sensemaking is a process that constructs identities. Weick underlines that: " $(\ldots)$ sensemaking matters. A failure in sensemaking is consequential as well as existential. It throws into question the nature of self and the world (1995: 14)".

The organisational life of a participant exists in joint actions, interlocked or bound behaviour, which he constructs into a meaningful life within the organisation. We must realise that someone does not invest everything in one group, but that he is member of several groups by way of interlocked behaviour. Members of different groups can prefer alternative actions. Every participant will have to take these potential alternatives into account. Therefore, there

\footnotetext{
${ }^{8}$ In comparison, we could think about border thinking: where - in principle - irreconcilable discourses meet, new vocabularies arise, established based on temporary definitions. Think of a debate about climate change in the chemical industry: economic-financial interests, shareholders, environmental activists, unions, stakeholders etc. will have to formulate temporary agreements - definitions - in an undecidable future in order to continue with the organisation. In this essay, we shall not further elaborate on this topic. See also Jozef Keulartz (2005: 21-41).

${ }^{9}$ Weick formulates the following seven core aspects of sensemaking, which are also characteristic to his own thought: Grounded in identity construction, Retrospective, Enactive of sensible environments, Social, Ongoing, Focused on and by Extracted Cues, Driven by Plausibility rather than accuracy (1995: 17-62).
} 
will always be an evaluation, a calculation. Consequently, the individual will appear to himself as principally multiple or ambiguous. Weick is clear about the multiple character of the self. From the beginning, Weick points out that 'I' should not be understood as singular, it is rather 'a parliament of selves'. Moreover, that multiplicity enables our flexibility and our ability to adjust. But insofar as that individual multiplicity would be problematic, the individual triesto unite them in an interpretation of the person, a constructed unity that retrospectively produces the integrity, the unity of the person.

In an organisation, a person is not valued because of his personality, but because of what he adds whilst acting, as actor. In this respect, Weick speaks of 'partial inclusion':

When there is partial inclusion or interlocking of some behaviours, additional behaviours of the individual may come under the control of this collective structure, because the person's desire to stabilize it (1979: 96).

The collective structure is protected by the individual because it assures him that the benefits of his connected behaviour will be preserved. Although Weick emphasises the psychological need for coherence, its collapse is an unavoidable and hence necessary part of that coherence. Interruptions, suspension of expectations, bring about emotions which incite 'sensemaking'. The purpose of sensemaking is to stabilise this chaos psychologically, not in reality but in identity. Weick writes:

It is precisely because ongoing flows are subject to interruption that sensemaking is infused with feeling. (1995: 45) (...) "The feeling of order, clarity and rationality is an important goal of sensemaking, which means that once this feeling is achieved, further retrospective processing stops (1995: 29).

The need for new meaning arises when the existing has exhausted her meanings, or has become inefficient or instable because of contradictions. The sensemaking of the event itself is in crisis here, not the event per se (1995: 176). Such processes, we call 'organising', which takes place constantly and within the entire organisation. They are loosely connected, but determinative for the survival of the organisation. The combination of loose links, the 'causal loops', can both increase effects of small actions, and strengthen the social influence within the interaction itself.

Adaptability, independence and social pressure are, for instance, elements of social influencing which are determinative for the course of the interaction process. Because this social dynamics especially plays a part in relatively small organisation-units, Weick deems the size of the organisation itself of lesser importance for the analysis. For most individuals, it is only natural that the greater part of the organisation is part of their surroundings.

\section{Enactment}

Another important concept that Weick uses is enactment (2001: 176). It is an active and creative moment in the 'production process' of gaining knowledge (doing that produces knowing). It divides the event (bracketing) and collects all elements which can - as unique collection - gain significance. In other words, it is an ordering which enables identification of elements that potentially can gain significance, sense. With this term, Weick refers to the 'act' which differentiates the undifferentiated and as a consequence creates the possibility of understanding. It is not about the finding, but about the creation of meaning. It is focused on action and operation. Therein, the pragmatism of sensemaking is mirrored. Actions are part of projects and enactment seems to follow the contours of an 'ongoing' project. Subsequently, 
sensemaking becomes subordinate to the continuity of the process, not to the goal, the place of arrival. ${ }^{10}$ The activity has primacy over the given, the act of creation over that which is found. That is why, as Weick will argue, the process of enacted sensemaking is necessarily retrospective.

Participants in the organisation try to build meaning around what binds them. Their sensemaking is rich in detailing and a source of order and value. It binds loose observations, experiences and arguments and classifies them in collections that support action, that counteract or that are irrelevant. The choice to act changes that which one understands. Making a choice adds value to the information. "We do not choose an antecedent good, but make something good by choosing it (1995: 159)".

\section{Cause Maps}

Besides sensemaking as process, we also have to look at the question what exactly sense, the discretionary totalising moment in the process, means according to Weick. In this respect, Weick speaks of cause maps. We would like to explain that concept as inner coherence, which refers to a factual and meaningful being-such-unity. It refers to the meaning of the stream of events with respect to one's own identity. The concepts 'unity' and 'totality' do not mean 'completeness' or a coherent and consistent non-contradiction. We have elaborately pointed out that Weick understands sensemaking and sense as an event which enables (inner) contradiction. Even more so: contradiction is necessary in order to enable sensemaking to generate adaption and evolution. Contradiction and diversity are constitutive characteristics of this totality and the basis of organisational dynamics.

Weick uses the concept cause maps when he speaks of arranging and creating coherence in information. A cause map is built from existing and new information. The new information is being "processed by the preceding memories" (1979: 211). A cause map is placed over a stream of ambiguous experiences and works self-affirming, it "creates the territories that it inhabits". It becomes space itself (1979: 140; 250). Cause maps reduce chaos, ambiguity and make reality containable by imposing a structure to it. Therefore, a cause map is an invention, a construction, not a discovery that is made in reality. 'Preceding memories' are helpful in sensemaking and are its basic structure as it were. Any preferred perspective can fulfil that role. In retrospect experiences are regarded as 'inevitable events' which lead to an already known result. The character of this 'inevitability', is, depending on perception, differently constructed.

\section{Meetings as Places of Sensemaking}

The 'I' from How can I know... is the acting and reflecting identity which becomes itself in the process, which develops itself as identity. To make sense of the situation, we are active in the situation itself as element of change (2001: 461). We stand in the situation, and whilst acting, we come to a common experience which - in the suspension, until - brings us to a construction of a sensible meaning of reality. Therefore, sensemaking has a constructive function towards 'two sides', both towards the subject (construction of identity) and towards the object (sense).

\footnotetext{
${ }^{10}$ We can recognize elements out of the algorithm of universal Darwinism: variance, reproduction and selection. This mechanism has no purpose outside itself otherwise than active survival.
} 
The emphasis is principally on the becoming character of sense and identity, not on a given (end)goal. Weick cites Walsh and Ungson's definition of organisation:

(...) a network of intersubjectively shared meanings that are sustained through the development and use of a common language and everyday social interaction (1995: 38).

In this formulation, we see that the place of the common does not lie in an identical meaning, but that it is temporarily retained as it were, perpetuated in the use of language and the factual cooperation. This is how the cognitive and the social are connected, coincidental and factual! The social order also comes into being by sharing of meaning, meanings that lean upon an implicit, shared common history and experience. This 'incomplete' consensus about how certain facts can be conceived, acknowledges the social order. Subsequently, through the interpretation of this order, patterns of meaning arise as a product of acting. These patterns exist independently of the interpretations that these patterns have produced. ${ }^{11}$

Shared meaning is not about an equal, but about a similar sense (1995: 188). The organisational coherence - shared meaning, common values - is usually described as organisational culture. Weick, on the contrary, argues that this is hard to accomplish because all people have different individual experiences. What participants do have in common however, is that the experience, actions and activities are shared. This shared experience can retrospectively be conceived as similar (and not equal) meaning. The explication of a shared experience leads to a common conceptual framework, which is referred to as 'culture'. "Culture, is what we have done around here, not what we do around here".

According to Weick, the organisation is located on the level of 'sharing', not on the level of abstractions. Sensemaking and sharing of sense or sharing of meaning exists due to the acknowledgment of a diversity of possible meanings. ${ }^{12}$ In organisations, sharing takes place in meetings: the chaotic meeting of difference (different experiences, opinions and ideas) makes sense and creates new vocabularies. ${ }^{13}$ The meeting of arguments, discussing, is the most important and sensemaking dynamic which makes or breaks an organization. Echoing Schwarzman, Weick says:

Momentarily, at least during the meeting, there appears to be an organization, and this appearance is reconstituted whenever meetings are constituted. (...) Meetings assemble and generate minorities and majorities, and in doing so, create the infrastructure that creates sense. This infrastructure varies in the frequency with which it generates good arguments, advocacy, and divergent thinking, as well as the spirit of contradiction (1995: 143-144).

Weick's hermeneutic vision allows contradiction, confrontation and interruption to be part of the sensemaking-process, just because of their 'disturbing' effect. That is why moments of consultation operate as founding places of sense. In that reality, where there is room for inconsistency and inconsequence, we suppose the living organisation which we experience on a daily basis. The opposition between the preservation on the one hand, and the void of sense

\footnotetext{
${ }^{11}$ Precursors of the sensemaking theory are sociologists Peter Berger \& Thomas Luckmann. In 1966, they wrote a book about social constructivism The Social Construction of Reality, Garden City, NY, Doubleday.

${ }^{12}$ In Art education experiments are going on in shared learning: practicing and thinking together bringing in different arts (painting, sculpture, movement, ballet, music, etc.). See 'Looking behind the corner' (Achter het hoekje leren kijken) of Isolde Vanhee \& Tom Van Imschoot (2015). In Rekto Verso. nr. 68 (p.50). This resembles the comparison Weick made between an organisation and a jazz improvisation.

${ }^{13}$ Verbs (acting) occur more often than nouns (status quo) (1995: 111). Also think of boundary work, the commons (public-private cooperation), on interfaces where different expertises start working together.
} 
on the other, is retained in organising and not lifted in favour of the dominance of flexibility or stability. Weick words it as follows: "ambivalence is the optimal compromise" (1979: 219). Although compromises are acceptable, they suppress the adjustment mechanism.

With the French philosopher Jean-Luc Nancy, we can say that Weick also gives an antimetaphysical basis to the subject by defining it as "being singular plural".

Nancy writes:

Being itself is given to us as meaning(Sense). Being does not have meaning(but is a mental construction). Being itself, the phenomenon of being, is meaning that is, in turn, its own circulation (an acting and communicative de-sign, a circularity of creation of meaning which has neither a beginning, nor an end) - and we are (construction of identity) this circulation. There is no meaning if meaning is not shared, and not because there would be an ultimate or first signification that all beings have in common, but because meaning is itself the sharing of being (social). Meaning begins where presence is not pure presence but where presence comes apart (in the suspension, the 'until') in order to be itself as such (Nancy 2000: 2).

What Nancy says here is that sharing of meaning equals sharing of being. In that sense, sharing is an event, a complex of acts which generates various meanings.

Meetings are moments of sharing of meaning with people who do not yet share experiences with others. ${ }^{14}$

\section{Shared Meanings, Moments in Connected Behaviour}

It is often being said that a group imposes norms onto its members. What underlies that idea is the assumption that there would first be a group that subsequently holds itself accountable for the rules, values and norms that hold a group together. According to Weick, we have to turn it around. Firstly, there is an overlap between persons regarding their values (beliefs), an overlap which appears as connected behaviour that is dominated by norms. The latter enables sustainable relations to come into being. When multiple persons meet in the act, there is a possibility that each of them can benefit from it in terms of satisfaction of needs or self-expression. This is only possible however, if the constant presence of the other is implied (1979: 90).

Weick builds up the logical train of thought which leads to group formation up as follows: firstly, in the meeting of activities, an idea comes into being about a convergence of mutual interest, and then a similar idea about how that can be achieved. Based thereon, a repetitive double interaction is established, a collective structure. The scope of their behaviour is limited before the group is formed. In this respect, Weick speaks of a convergence, a de-sign of different ideas. Participants in a collective structure share space, time and energy but they do not have to share vision, aspiration, desire or intentions. The latter comes later on, or probably never. The idea that groups form around shared goals is turned around by Weick, and replaced with the idea that groups form around shared means. Groups form between people with different goals!(1979: 91)

Therefore, the issue is a diversity of goals and a communality of goods. Only when the participants converge on joint behaviour, a subtle move sets in from diversity to communality

${ }^{14}$ Weick refers to Heidegger in this respect, the being thrown and to Dilthey and his 'hermeneutic circle' (1995:44). 
of goals, where diversity is somewhat suppressed. Somewhat, because as we have seen before: "ambivalence is the optimal compromise".

\section{(dis)continuity}

According to Weick it is incorrect to speak in terms of 'results' in relation to sensemaking, because this ignores the continuity of the process itself. He writes: ... 'there is no result of process but only a moment in process'. Sensemaking is ongoing. One can only understand interruption as an impulse to sensemaking starting from a sense of what continuity means. To Weick there are thus two aspects that are mutually involved, pure duration and interruption. He connects pure duration with Heidegger's idea of 'geworfen sein'. Herein lies the unavoidable social character of human acting: we are physically ... somewhere. According to Weick the situation of Dasein as geworfen sein (being as a historical and empirical existence) und Hinfälligkeit (sensibility, susceptibility) is best described by way of the metaphor 'meeting'. We can recognize this 'geworfensein' and 'continuously experience' as organizational issues. Streams, problems, solutions, people and choices flow through the organisations and converge and diverge irrespective of the human intention. Even solutions and problems are easily confused.

When people are interrupted, they react emotionally at first because of the confusion this interruption causes, only subsequently they can give meaning to this interruption. Moreover, people constantly generate interventions themselves, through which reality permanently changes. Following Mead, Weick compares the memories and associations to prior experiences that have permanently changed reality to a 'parliament of selves', through which he relocates the acting person as an agent amidst a continuously changing environment. ${ }^{15}$

Postmodernist Lyotard takes it even a step further and sees interruption as a rupture, necessary for the recognition of the deficiency of the other. Through interruption time (and deficiency) is introduced. Interruption is an act of survival, a postponement of 'completion'. Completion is equal to stagnation, to death (Manschot 1995: 235). Lyotard precisely considers the ethical as interruption. It is the 'susceptibility to obligation' that is separated from politics as 'the threat of dispute (...) [and] the diversity of purposes (Lyotard 1983: 200 and 249).' An interruption triggers a physical defence mechanism that leads to a (functional) (re-)action. This action as a consequence of an interrupted expectation pattern becomes emotionally charged and this combination of action and sensation leads to sensemaking, according to Weick. Foucault describes 'rupture' as a critical event after which we will never think, feel or act the same. The rupture discloses the critical spaces in which reason can be experienced again. In this way, aspects such as misunderstanding, failure, mistakes, conflict, contradiction and exclusion play a part in understanding the organisational dynamics. In order to manage the resulting confusion, individuals actively make sense of that experience retrospectively, in social interaction. Sensemaking does not cancel diversity, but preserves it as factual and potential contradictions. This can also work as a disruption giving rise to a crisis. Sensemaking finds its ground in the unsolved diversity. People want to express their own individuality against the interdependence of the other group members. This movement does not come to a halt. In crisis, it is specifically the sensemaking of the event itself which is undergoing a crisis.

\footnotetext{
${ }^{15}$ In 1997, Slawomir Magala wrote an interesting review for Organization Studies, 18/2 on Weick's organisational theory, where he concludes that Weick's treatment of agents as parliaments of selves and the organisation as a negotiation parlour leads to an anti-(hierarchical) authoritan perspective on the organization (1997: 333). We think this was an act of clairvoyance of organisational reality in the 21 st century.
} 
Some aspects of the environment have meaning, while others do not. This can give rise to a 'contrast-effect' in the organisation: ambiguity. If an existing, collective structure does not provide stability and order in a dynamic world, the people in this organisation will start behaving more individually. In this new stage of development, Weick's pragmatically and incompletely formed common purposes can disintegrate again into 'diverse means', or the connected behaviour can be broken. The latter situation can arise in the case of division of labour, reorganisation or specialisation. People find a new (sub) unit with its own creation of meaning. Therein, the sense of the bigger picture loses its meaning. We especially see this with experts who are less inclined than others to share with other people. If an organisation does not have a stable common purpose and the shared meaning of sense keeps disintegrating, then the emphasis on shared norms and values of an organisation is equally problematic. The meaning that brings unity is based on a diversity that inevitably keeps manifesting itself as such. In Weicks view, contradiction, confrontation and interruption are part of the continuous sensemaking process, exactly because of their 'disruptive' effect (Weick 2001: 100-124).

\section{Retrospection and Time}

One of the highly criticised aspects of Weick's theory concerns the retrospective nature of sensemaking departing from 'action precedes thought', a fundamental position.

A crucial property of sensemaking is that human situations are progressively clarified, but this clarification often works in reverse. It is less often the case that an outcome fulfils some prior definition of the situation, and more often the case that an outcome develops that prior definition (1995: 11).

The retrospective nature of sensemaking revolves around the analysis of 'meaningful lived experience' and the fact that the 'perceived world is in reality a past world' (1995: 24). Weick clarifies this by pointing out that 'time exists in two distinct forms, as pure duration and as discrete segments'. The first form can be described as 'a stream of experience', where experience is explicitly written in singular (1995: 25). In other words: by placing the experiences within the continuity (pure duration) they become experience. It is, as Weick calls it, 'lived experience, they know what they are doing only after they have done it'. The observation, seeing or feeling, renders time discontinuous and makes experience into $a$ past experience, 'seeing that something is done'. Seeing makes doing into done and, ultimately, into sense, so that we can say that sense exists only as past. That is why he can speak of the present influencing the past. Of course not in the sense that causal relations are turned around, as some critics claim, but we are only aware of what we have done and not of what we are doing. He formulates it even more sharply citing Pirsig, who states:

(...) an intellectually conceived object is always in the past and therefore unreal. Reality is always the moment of vision before intellectualization takes place. There is no other reality (1995: 24).

In hindsight, experiences are seen as an inevitable sequence of events that lead to an already known result. The past is reconstructed from the knowledge of the outcome. This means that the memory serves the result and that we do not remember events, but that - given the result we remember the events that have led to this result.

Critics separate past and future, each as a separate meaningful reality. According to them, retrospective sensemaking gives meaning to the past, while prospection gives meaning to the 
future, the realm of possibilities. In our opinion, the heart of the misunderstanding lies in this notion. For this criticism does not take into account the notion that the nature of sensemaking is heuristic, that is to say that meaning is the result of sharing of meaning and refers to total cohesion. Retrospection relates to the matter of sensemaking, the performed act. However, the result of this sensemaking process exceeds this act by placing it in relation to other acts, events, timeframes, etc. It is this cohesion that produces sense, as words refer to the language in its entirety. In this respect Weick states:

(... ) If sensemaking were not retrospective, we would be forever incapable of making sense of our past-whether real or imagined. And if sensemaking were not also prospective, we would be forever at a loss when asked where we want to go (1995: 28).

The sense that thus appears, refers to a totality that generates its own past, present and future. It is the future of this constructed and signified reality. The sense of the event makes the sense of its future possible. Weick keeps emphasising that it is not the discovery of the meaning of the experience that is important, it is not an interpretation of a text. On the contrary, according to Weick it is the kind of attention given to this experience that determines meaning. In this sense, prejudice plays a part, and this is important because reflection is 'over-determined' and multiplication creates meaning. The dimension of the possible does not refer to what is indefinitely logically possible, but to what is definitely actually possible, which results from the reality that is construed by the sensemaking process.

Weick's opinion that we do not interpret the act but our relation to that act, suggests he would support such an analysis. He writes:

... the idea that sensemaking is self-referential suggest that self, rather than the environment, may be the text in need for interpretation. ... I make sense of whatever happens around me by asking, what implications do these events have for who I will be? What the situation will have meant to me is dictated by the identity I adopt in dealing with it. And that choice, in turn, is affected by what I think is occurring. What the situation means is defined by who I become while dealing with it or what and who I represent (1995: 24).

The notions of continuity and discontinuity are located on the side of the sensemaker himself and illuminate because of changes in perspective. "Meaning is not 'attached to' the experience that is singled out. Instead, the meaning is the kind of attention that is directed to this experience (1995: 26)".

Derrida helps us to better understand Weick's notion concerning the retrospective nature of sensemaking. According to Derrida, the abovementioned misunderstanding is the result from holding on to the idea that past and future arise from the now, while it is the other way around: past and future are the conditions for a potential now. It is her original supplement. In the now, we are no longer originally and completely within ourselves. The now is the transition between a no longer and a not yet. It is a bursting apart of presence that withdraws itself and postpones indefinitely. This space of 'non-presence', of not being identical to oneself, is the space where meaning is ascribed. In his aforementioned key phraseHow can I know what I think until I see (hear) what I do? Weick calls this 'until'. The present is present to itself only afterwards. The ascribing of meaning redeems the lack of presence, there is a desire for presence (Derrida 1967: 207-208).

Critics also direct their objections to the alleged 'reverse of causality', which means that 'sense' and 'act' would be reversed in time. That thought can only arise if causality is conceived 
as a logical succession of acts, sense being the cause of the action that preceded in time. But it is incorrect to conceive sense and action in this way. After all, it is about the reflection on this experience which is in no way determined or univocal. This reflection can never be seen as a causal relation. Sense does not exist in a causal but in a judgmental relation towards the experience, in which values and priorities lead to unambiguity in an over-determined reality.

\section{Plausibility}

As we have already seen, sense is shared during meetings (sharing of meaning). In this respect, Weick speaks of a condensing of sense as a shared reality, without being able to speak of an identical understanding of that reality. This gives rise to the question of the basis of such a condensing, which is merely temporary and incomplete. A reference to an out there that could be standardising therein is not possible. As we have indicated before, the world does not present itself to us as a fixed fact, but the basis for our knowing should be sought in its 'groundlessness'. According to Weick, sensemaking is about plausibility, pragmatics, coherence, reasonability, creation, invention and instrumentality. It is not and cannot be dependent on an accurate reproduction of a perceived 'reality'. Sensemaking has a merely relative relation to truth. "... people will believe what can account for sensory experience but what is also interesting, attractive, emotionally appealing, and goal relevant (1995: 57)." Sense is socially acceptable and credible. All possible truth is practical.

Beliefs that counteract interruptions and facilitate ongoing projects are treated as accurate. Accuracy, in other words, is project specific and pragmatic. Judgments of accuracy lie in the path of the action (1995: 59).

This caution drives him to choose the thinking of psychologist and philosopher William James above Derrida's deconstructive thinking (Weick 1995: 38). James' famous question 'is life worth living?' followed by the answer 'yes', is the beginning of the theory of sensemaking and enactment. With his statement 'faith is instrumental to sensemaking', Weick gives away his preference for James. The finding that there is no stable and uniform external world, but that our own interpretations and judgements shape the world, presupposes a trust in a 'self-fulfilling' mechanism which guarantees the creation of an organisational reality based on interpretations.

At different times, Weick speaks of the causal relations 'which are irreversible'. By this he means that this relation is arbitrary in the sense that it trades its primary causal relation for a relationship or cohesion. Here he merely refers to an external cohesion, and not to a conceptual one. That is also why, in his later work, he does not speak of cause maps anymore, but connects the sensemaking to stories: inductive generalisation. Instead of indicating the primacy of the argumentative two-dimensionally in the cause map, he later places the primacy in the narrative, the plausibility, the conviction, which is not necessarily (merely) justified causally and accurately.

If accuracy is nice but not necessary in sensemaking, then what is necessary? The answer is, something that preserves plausibility and coherence, something that is reasonable and memorable, something that embodies past experience and expectations, something that resonates with other people, something that can be constructed retrospectively but also can be used prospectively, something that captures both feeling and thought, something that allows for embellishment to fit current oddities, something that is fun to construct. In short, what is necessary in sensemaking is a good story (1995: 60).

The story is a form of description which 'transforms events into historical facts by demonstrating their ability to function as elements of completed stories'. It is fiction, but 'no 
more fictional than any other product such as thought since abstraction, schematization, and inference are part of any cognitive act (1995: 128)'. Stories can generate meaning, especially because they too are built sequentially. ${ }^{16}$ A story keeps unlike things together, long enough to generate energy and to give direction to action, which is plausible enough to retrospectively make sense of what happens, and binding enough so others will also want to contribute in favour of the survival of this binding.

\section{Implications for Management}

Based on the foregoing we can at least make the following observations:

- The smallest unit of analysis of the organisation is not the individual but a (action-) relation that does not condense itself to 'a group' but to 'shared experience'.

- This relation is practical, it is in fact bounded behaviour and thus cannot be understood as a relation between participants.

- Because this action-relation is the basis, an organisation is primarily an activity and not a static whole, a verb instead of a noun.

- The organisation is in principle 'without ground' and sensemaking is the basis for the understanding of the organisation and its environment.

- Sense is based on an appreciative judgement of shared experience.

- The core of organising is 'sharing of meaning' which condenses itself through (narrative) language usage.

- Sensemaking is also identity-constructing.

Weick has given us a theory about organisations which emphasises the action and not the planning, in which continuity is rooted in discontinuity, stability in successive crises and the cohesion does not lie in community of purpose, but in a diversity of purposes of participants and in the common practical experience of working together. Incoherence and inconsistency have become aspects of the conception of organisation and are therefore no longer an external threat. The boundaries of Weick's organisation and therewith the conception 'environment' are diffuse and indefinite. Everything technicians from the 19th century have passed on to us seems to have crumbled, including calculative thinking itself. Weick makes it possible for us to make sense of our modern world.

'Sharing of meaning', the exchange of meaning and values, is central. In this respect we agree with Nancy, who formulates it as follows:

There is no meaning if meaning is not shared, and not because there would be an ultimate or first signification that all beings have in common, but because meaning is itself the sharing of being (Nancy 2000: 2).

\footnotetext{
${ }^{16}$ Magala refers in this respect to Paul de Man. His position has been summarised by John Phillips as follows: 'The grounds of literary meaning (and by extension all meaning) must be located in rhetoric rather than in any of the other possible dimensions (form, content, reference, grammar, logic etc.). But a rhetorical reading cannot guarantee authority over interpretations. Therefore there is no authority that can guarantee a reading. This doesn't license us to read a text just anyway we want to. Rather it commits us to readings that take full account of the possibilities and limits of reading (and writing) generally. One name for these possibilities and limits might be deconstruction (https://courses.nus.edu.sg/course/elljwp/deman.htm)
} 
Managing becomes the managing of sense, sharing of meaning, of diversity and oppositions. A manager who sets himself as an example and tries to push through one dominant sense, denies the necessity of diversity and undermines the organisational dynamics itself.

If we take this conception of organisation as a point of departure, we cannot get around the question which consequences this dynamical conception of organisation has for the theory and practice of organising today, and for thinking about management and leadership. If the nucleus of 'organising' is the bounded behaviour and not the individual, and if its existence is rooted in the sharing of meaning, then the individual - or individual leadership - can no longer be at the heart of our research. We must then focus on the dynamics of organising itself. Leadership presents itself as a stimulator towards sharing of meaning, which can transform 'the way it is' into 'the way it could be'. Leadership represents the escape from what seems incomprehensible, chaotic and indifferent to us. It takes us through living language from a world we cannot control. Within this context however, leadership can no longer be seen as a personal quality, it is a movement that legitimises itself only afterwards (Wesseling and Langenberg 2013: 185-201).

Of course there are also consequences for other fields of practice and research, such as organisational ethics. We will have to verify how the consequences of Weick's conception of organisation relate to diversity in values and norms. To what extent do values and norms depend on sensemaking and sharing of meaning? Are we generally inclined to see the context as a contribution to the evaluation of behaviour? Weick makes it impossible to see sense as (a) sense giving totalising context(s). Again and again we will have to construct these shared norms and values, rooted in shared meaning of experience in action and in dialogue. We can probably only find a basis for postmodern and multicultural organisational ethics, if we are able to push through this diversity of values and norms which correspond with a diversity of meanings,

The above-described concept of leadership is also relevant for moral leadership. This is often merely conceived as exemplary behaviour of a manager, but within this framework it is rather the creation of a reality of responsibility and the managing of sharing of meaning. Would it not be logical to further study this aspect within the sensemaking process and especially within the 'sharing of meaning'? How can the management of integrity be defined when it is mainly about the management of diversity? What should we think about (management) training that aims at developing moral conscience, mainly by resolving pre-structured cases, and does not look at the real process, i.e. sensemaking itself? How should we regard tests of individual integrity and other psychometric instruments in this respect?

Weick agrees with Walsh and Ungson (1991), who describe the organisation as "a network of intersubjectively shared meanings that are sustained through the development and use of common language and everyday social interaction (1995: 38-39)". In this case, should we not focus more on the role of language, the stories and the rhetoric within organisations?

Finally, it comes down to the fact that the people who come together at a certain moment for a negotiation, a conversation, a strategic, political, national or international meeting, open up their judgement to the other. In the evolution of organisation we constantly discern a preference for calculative thinking. This has a twofold effect:big companies, national government, universities and large financial institutes lose credibility and are no longer the figurehead of (economic) stability and progress. Secondly, the effect on society is unmistakeably visible in the growing inequality and in the discontentment involved. Calculative thinking does not take sensemaking into account. It does not understand crises as a crisis of calculative thinking itself, of its attempt to merge the multidimensionality of language with the one dimensionality of calculation. 
'Organising' as described by Weick, goes way beyond one single idea of a classical organisation. Dynamics makes sure that 'theorder' of society repositions itself constantly about and within the organisation. Sharing of meaning and sensemaking do not happen solely within the walls of the organisation, but are inside all of us and happen everywhere. This becomes most visible in public-private collaborations, where the management of, the working in and the enjoyment of property is a common act and is determined by the constant sharing of meaning ánd being.

Modern, global society consists of arbitrary fluid (temporary) networks. The porous separation between the private and the public fades, which constantly evokes and strengthens discussions on boundaries. An organisation is the prototype thereof, where a proliferating diversity both pushes back and oversteps boundaries and demands new boundaries. This fundamental movement, which does not stop, must be understood if we are to manage it. In our opinion Weick can assist us in that understanding.

Open Access This article is distributed under the terms of the Creative Commons Attribution 4.0 International License (http://creativecommons.org/licenses/by/4.0/), which permits unrestricted use, distribution, and reproduction in any medium, provided you give appropriate credit to the original author(s) and the source, provide a link to the Creative Commons license, and indicate if changes were made.

\section{References}

Daft, Richard and Karl Weick. 1984. Toward a model of organizations as interpretation systems. In Making Sense of the Organization, 241-259. Oxford: Blackwell Publishing.

Derrida, Jacques. 1967. De la grammatologie. Paris: Les Editions de Minuit.

Derrida, Jacques. 1972. Positions. Paris: Les Editions de Minuit.

Heidegger, Martin. 1996. The principle of reason. Transl. Reginald Lilly. Bloomington: Indiana University Press.

Van Den Hengel, John W. 1982. Home of meaning: hermeneutics of the subject of Paul Ricoeur. Washington

D.C.: University Press of America.

Keulartz, Jozef. 2005. Werken aan de grens. Budel: Damon.

Khandwalla, P.N. 1977. The design of organizations. New York: Harcourt, Brace Jovanovich.

Langenberg, Suzan. 2008. Kritiek als des-organisatie. Bedrijfsethiek en waarheidspreken. Antwerpen: Garant.

Langenberg, Suzan. 2011. Dis-organizing as an act. In Spiritual humanism and economic wisdom, ed. Henk Opdebeeck and Laszlo Zsolnai, 99-111. Antwerpen: Garant.

Lyotard, Jean-François. 1983. Le différend. Paris: Gallimard.

Magala, Slawomir J. 1997. The making and unmaking of sense. Organization Studies 18(2): 317-338. EGOS.

Mallet, Marie Louise, and Ginette Michaud. 2004. Derrida, 21-34. Paris: Editions de 1'Herne.

Manschot, Henk. 1995. Het onmenselijke als ervaring en als experiment. In Lyotard lezen, ed. R. Brons and H. Kunneman, 229-240. Amsterdam: Boom.

Nancy, Jean-Luc. 2000. Being singular plural. California: Stanford University Press.

Vanhee, Isolde, and Tom Van Imschoot. 2015. Achter het hoekje leren kijken (Looking behind the corner). In Rekto Verso. nr. 68. Borgerhout, Rektoverso.

Walsh, J.P. and G.R. Ungson. 1991. Organizational Memory. In Academy of Management Review, vol. 16: 5791. New York: Academy of Management.

Weick, Karl. 1979. The social psychology of organizing. New York: Newbery Award Records.

Weick, Karl. 1995. Sensemaking in organizations. London: Sage Publications.

Weick, Karl. 2001. Making sense of the organization. Oxford: Blackwell Publishing.

Weick, Karl, and Kathleen Sutcliffe. 2007. Managing the unexpected. San Francisco: Wiley.

Wesseling, Hans and Suzan Langenberg (eds.). 2013. Over leven in werk. Cahiers Campus Gelbergen nr. 2. Antwerpen: Garant.

Dr Suzan Langenberg holds a PHD in Philosophy from Radboud University, Nijmegen, Netherlands. She is director of Diversity and is program manager of Campus Gelbergen. Suzan researches the place and effect of criticism in private and public organisations. 
Drs Hans Wesseling is senior consultant in the area of Integrity management. He studied Philosophy and Economics at the University of Tilburg and Nijmegen. He is interested in the role of the Human Resources profession in developing and managing moral behavior in companies. Together with Suzan Langenberg he published Over leven in werk, Garant 2013. 